\title{
A PROGRAMME FOR FACILITATING THE OCCUPATIONAL ADJUSTMENT OF BLACK CAREER EMPLOYEES ${ }^{1}$
}

\author{
CJ.H. BLIGNAUT ${ }^{2}$ \\ DEPARTMENT OF INDUSTRIAL PSYCHOLOGY \\ UNIVERSITY OF SOUTH AFRICA
}

\section{OPSOMMING}

Die toenemende opgang van Swartes in die Suid-Afrikaanse beroepslewe hou belangrike implikasies vir die bedryfsielkunde in. Sommige hiervan hou verband met die skepping van geleenthede vir vordering, arbeids- en menseverhoudings, opleiding en so meer. In hierdie studie word werketiek ondersoek. Daar is gevind dat werkwaardes wat met werketiek geassosieer kan word, so verander kan word dat dit positief reflekteer in werksprestasie.

The progress of Blacks is not only noticeable, but also eminent in various walks of life in South Africa. The need to progress and to facilitate progress is evident from economic realities, political, technological and other considerations. At the heart of the present-day situation seems to be, not so much the extent, but the manner of facilitating the progress of Blacks in Southern Africa. Differences of opinion in this regard, although most apparent amongst politicians, may also be found amongst specialists operating in a diversity of fields. It is suggested that this also applies to personnel managers in general and to training specialists in particular. In this study an attempt was made to explore an avenue, relevant to training, of facilitating the progress of Blacks in industry and of providing empirical data as to a possible source for future planning.

The impetus for this study originated from casual observation and found substance in sociological arguments aimed at explaining the development of "modern" capitalism. As an introduction to the particular approach followed in this study, it seems appropriate to contemplate some of the ideas put forward - not to participate in sociological discourse and

\footnotetext{
${ }^{1}$ The author is in debt to Mr Mike Alfred, Personnel Manager, AECI, Modderfontein Factory, and his staff for their kind assistance in conducting this research.

2 Presently at the Rand Afrikaans University, Johannesburg.
} 
eventually to side with a particular school of thought, but in order to take cognisance of the content in some of the concepts that are employed.

The "modern capitalistic system" can be characterised in different ways. It is inconceivable, however, to attempt such a description thereof, whether in regard to the origin or development, the maintenance or demands of the system, without referring to human endeavour. One way of doing so in the humanities has been to employ the concept of the "spirit of capitalism". This concept originated from and became known through the works of Sombart and Weber (Green, 1959). A concise and accurate description of the "spirit of capitalism" is difficult to achieve. First, because the kind of capitalism to which the "spirit" is linked has to be made explicit. Second, because that stage of the development of capitalism, to which reference is made, has to be specified. Third, because it is unlikely that any description of an abstract concept such as the "spirit of capitalism" provides sufficiently for cognitive differences. Notwithstanding these provisions, it is essential that some indication of the meaning of the concept be given. For this purpose use will be made of the work of Weber (1950).

As a preamble to his exposition on the "spirit of capitalism" Weber relies on the autobiography of Benjamin Franklin. Some of the quotations made by Weber (1950, pp.4850) are worth repeating:

"Remember, that time is money. He that can earn ten shillings a day and goes abroad, or sits idle, one half of that day, though he spends but sixpence during his diversion or idleness, ought not to reckon that the only expense; he has really spent or thrown away, five shillings besides".

"For six pounds a year you may have the use of one hundred pounds, provided you are a man of known prudence and honesty".

Weber uses these and similar quotations as a background to his thesis that the "spirit of capitalism ... describes that attitude which seeks profit rationally and systematically", devoid of traditionalisms. It seems that this "spirit" is one of complete ".. devotion to the calling of making money". This attitude toward material goods seems to surpass their utility as a means of satisfying essential material needs, in that the goods provide opportunity for further economic acquisition. In addition to pointing out that the "spirit of capitalism" operates in a particular manner, Weber is careful to stress that it does so in a justifiable style. He indicates, for example, that it fails if it is not scrupulous, ascetic, just, active and free of greed. 
The "spirit" implies a set, a readiness, and "whoever does not adapt his manner of life to the conditions of capitalistic success must go under, or at least cannot rise". Before examining this set or manner of life, it seems appropriate to conclude that the picture emerging from the above, though vague and incomplete, represents something of the inner characteristics of the system into which the Blacks are becoming absorbed. It is suggested that the "spirit of capitalism" manifests itself increasingly as this system is penetrated.

The set of manner of life referred to above can be treated as what is known in sociological circles as work ethics. It appears safe to say that the "ethics of a people" are derived from their particular culture which develops continuously. In order to gain some understanding of the nature of present-day work ethics, it seems feasible to take a glimpse at that branch of culture (viz. religion) which apparently plays a significant role in the formation of work ethics. As is the case with race, it is difficult to write with scientific objectivity about this particular contribution of religion, for as well as being unable to present a complete picture, one has to make allowance for the possibility of a writer's bias, in addition to a reader's bias. In the present context a way around the problem seems an explicit focussing on a particular set of doctrines and an acknowledgement that it represents only one of a possible number of contributory and interacting factors which are inherent in the shaping of presentday work ethics. These doctrines have been interpreted by Weber (1950) as:

- $\quad$ the conception of the calling, which implies that everyday worldly activity assumes religious significance

- $\quad$ the doctrine of predestination, with the implication that every person through absolute faith had to be convinced in himself of being elected, which in turn implies intense worldly activity as to eliminate religious uncertainty, and

- $\quad$ asceticism, through rational worldly conduct as opposed to monastic asceticism, so as to overcome undesirable temptation.

Bearing in mind the influence of religion at the time of the formulation of these doctrines, as well as their implied impact on the motivation to work, it is not surprising that Weber proposed that the protestant reformation has a significant influence on the development of "modern" capitalism. Be that as it may, it is suggested that the behavioural consequences of the above orientations, remoulded, refined and re-defined into the presentday work ethic, are qualities sought after in prospective employees and promotees. This is evident in the apparent congruence between the demands for survival and progress implied by 
the "spirit of capitalism" and the orientation to life formed by the conception of this work ethic.

Before attempting to define the behaviour associated with work ethics, it is appropriate to point out that this ethic represents a set of conditions as it were, into which the individual is born and brought up. Instrumental to this is the home and school (with clichés such as "labour ennobles"), religion (with statements such as "use your talents"), psychology (with selfactualizing theories) and the like - each contributing to creating the so-called "achieving society". It would seem feasible to suggest that the process of (work) ethic development involves very little "formal training"; that its formation appears to be taken as a natural byproduct of society; to the extent that, by the time an individual engages in economic activity, it is assumed not only that the individual will manifest a particular set of values towards work, but also that these will be in congruence with those of the employing organisation.

It is not difficult to translate work ethics into terms more operational; the only proviso seems to be that the terms are descriptive of the "ideal" employee. A systematic derivation from the so-called Protestant ethic, however, has been performed by Wollack, Goodale, Wijting and Smith (1971) and resulted in the following:

- $\quad$ pride in work

- job involvement

- $\quad$ preference to be active

- $\quad$ awareness of job status

- $\quad$ desire to strive upwards

- $\quad$ acceptance of responsibility

It is proposed that emphasis on these and similar qualities differs from (sub)culture to (sub)culture. Besides the results of indirect historical analysis, which are met with criticisms such as "One might wonder ... whether Calvin was a Calvinist ... " (Green, 1959), empirical evidence to this effect has been provided by Lenski (1961), Bouma (1973), Blood (1969) and Aldag and Brief (1975). Mirels and Garrett (1971), Wollack et al. (1971) and Blood (1969) developed measures by means of which the proposal could be examined.

Some suggestions that work ethic differences between Blacks and Whites exist in South Africa comes from the work of Biesheuvel (1955) who points out that ethics originate in the school, church and home, but that "in the case of many Africans, family life has suffered serious disintegration and even where it has not done so, only imperfect guidance can be 
expected from parents who in many instances are nearer to tribal life than to Western culture". Also, much of the source of ethical orientation as expressed in European models is not "uniformly favourable, and suitable as objects of identification".

The aim of this investigation was to examine the possibility of facilitating the advancement of Blacks by reducing possible word ethic differences through a suitable training programme. Specifically it was hypothesised that the programme developed for the study would lead to significant positive changes in the work values of Blacks and that these changes in turn would lead to significant positive shifts in the perception by supervisors of the job performance of the trainees. Possible effects of the programme on other job related variables such as job satisfaction were also examined.

\section{METHOD}

\section{The programme}

It was envisaged that the above objectives could best be met in an industrial situation through a programme which:

- $\quad$ did not extend over too long a period

- $\quad$ made explicit the peculiarities of a business concern, and the conditions and modus operandi for its long term survival, particularly regarding its profit motive

- demonstrated differences in career prospects resulting from different orientations to work

- demonstrated differences in the reaction of others (that is supervisors) resulting from different orientations to others and to work

- $\quad$ provided maximum trainee involvement on a cognitive and affective basis

- $\quad$ could be administered on a small group rather than taking the form of individual counselling sessions

- $\quad$ could be administered to trainees with a minimum educational level of standard eight.

With these criteria in mind a programme based on the techniques of role play and management games was designed. The programme consisted of three sessions, each of approximately three hour's duration. The thrust of each session may be described respectively as understanding the nature of business, appreciating the influence of work values and 
understanding social perceptions. The programme was subjected to a trial run using seven participants so as to iron out any administrative difficulties and ambiguities.

\section{Criteria}

In order to examine the hypotheses formulated above, use was made of the work ethic scale of Mirels and Garrett (1971) and the job performance scale of Beatty and Schneier (1977) as criterion measures. Because of the exploratory nature of the investigation a number of other criteria which, on face value, could be affected by the programme, were selected in addition to the main criteria. These were: The job satisfaction scale of Brayfield; The work alienation scale of Pearlin; The attitude towards supervisor scale of Nagle (Robinson, Athanasiou \& Head, 1969) and degree of Westernisation and acceptance of authority of the TAT-Z.

\section{Participants in the study}

Twenty subjects were randomly drawn to participate in the study from the employees of a large manufacturing concern who had attained the required educational level. The participants were randomly assigned to a control and an experimental group. The latter was subjected to the proposed programme.

\section{Design of the experiment}

Individuals of both the control and experimental groups were measured on each of the criteria before the programme was administered to the latter group. Immediately after administering the programme a second set of measurements was taken on the two groups of subjects on those criteria on which such measurement appeared feasible. Since this measurement occurred before the subjects returned to their jobs, it was felt that measures on job performance, work alienation and attitudes towards supervisor could be premature. Approximately one month later a third set of measurements on all the criteria was taken for both groups. Where possible repeated measures were based on splits of the original instruments. The measuring procedure is summarised in Table 1.

\section{RESULTS AND DISCUSSION}

Due to the demands imposed by the work situation in the concern where the study took place, a complete set of measurements on only seven experimental and five control group 
subjects could be secured. The results of the investigation were analysed by means of the analysis of variance for repeated measures on groups of unequal sizes. Statistical significance could only be obtained on the criteria of work ethics and job performance. The results of the analysis of variance on these criteria are summarised in Table 2.

\section{$\underline{\text { TABLE } 1}$}

\section{CRITERION MEASURMENT}

\begin{tabular}{|l|c|c|c|}
\hline \multirow{2}{*}{\multicolumn{1}{|c|}{ CRITERION }} & \multicolumn{3}{|c|}{ MEASURED FOR BOTH GROUPS } \\
\cline { 2 - 4 } & $\begin{array}{c}\text { Before } \\
\text { Programme/ } \\
\text { First } \\
\text { Occasion }\end{array}$ & $\begin{array}{c}\text { Immediately } \\
\text { after } \\
\text { Programme/ } \\
\text { Second } \\
\text { Occasion }\end{array}$ & $\begin{array}{c}\text { Approx. one } \\
\text { month after } \\
\text { Programme/ } \\
\text { Third } \\
\text { Occasion }\end{array}$ \\
\hline Work ethic & Yes & Yes & Yes \\
Job performance & Yes & No & Yes \\
Job satisfaction & Yes & Yes & Yes \\
Work alienation & Yes & No & Yes \\
Attitude towards supervisor & Yes & No & Yes \\
Degree of westernisation & Yes & Yes & Yes \\
Degree of acceptance of authority & Yes & Yes & Yes \\
\hline
\end{tabular}

To analyse the results further, use was made of the $t$ statistic (Kirk,1968). The results of these tests pertaining to the work ethic criterion are shown in Table 3. 
$\underline{\text { TABLE } 2}$

RESULTS OF THE ANALYSIS OF VARIANCE FOR THE WORK ETHIC AND JOB PERFORMANCE CRITERIA

\begin{tabular}{|l|c|c|c|}
\hline \multicolumn{1}{|c|}{ SOURCE } & $\begin{array}{c}\text { SUM OF } \\
\text { SQUARES }\end{array}$ & $\begin{array}{c}\text { DEGREES } \\
\text { OF } \\
\text { FREEDOM }\end{array}$ & F-VALUE \\
\hline WORK ETHIC & & & \\
Group of Participants (A) & 143,72 & 1 & 1,48 \\
Error & 968,96 & 10 & \\
Measuring Occasion (B) & 24,55 & 2 & 1,68 \\
A X B & 62,99 & 2 & $4,31^{*}$ \\
Error & 145,90 & 20 & \\
JOB PERFORMANCE & & & \\
Group of Participants (B) & 0,37 & 1 & 0,00 \\
Error & 1726,72 & 13 & \\
Measuring Occasion (B) & 68,78 & 1 & $8,07 *$ \\
A X B & 46,67 & 1 & $5,47 *$ \\
Error & 110,86 & 13 & \\
$* \mathrm{p}<0,05$ &
\end{tabular}


TABLE 3

RESULTS OF t-TESTS ON WORK ETHIC AND JOB PERFORMANCE DATA

\begin{tabular}{|l|c|}
\hline \multicolumn{1}{|c|}{ DIFFERENCES } & t-VALUE \\
\hline WORK ETHIC & 0,50 \\
Between groups on first occasion & 1,26 \\
Between groups on second occasion & $3,04^{*}$ \\
Between groups on third occasion & 0,25 \\
Between first and second occasion for experimental group & $3,58^{*}$ \\
Between first and third occasion for experimental group & $3,83^{*}$ \\
Between second and third occasion for experimental group & 1,96 \\
Between first and second occasion for control group & $2,14^{*}$ \\
Between first and third occasion for control group & 0,17 \\
Between second and third occasion for control group & \\
& \\
JOB PERFORMANCE & 0,73 \\
Between groups on first occasion & 0,87 \\
Between groups on second occasion & $5,18^{*}$ \\
Between first and third occasion for experimental group & 0,53 \\
Between first and third occasion for control group & \\
$*$ p < 0,05 & \\
\hline
\end{tabular}

$* \mathrm{p}<0,05$

From Table 3 it would appear that the experimental and control groups differed significantly on the third occasion of measurement and that the scores obtained fro the experimental group differed significantly between the first and third as well as between the second and third occasions of measurement. The control group appears to have scored significantly better on the first than on the third occasion of measurement. These results are illustrated graphically in Figure 1. 


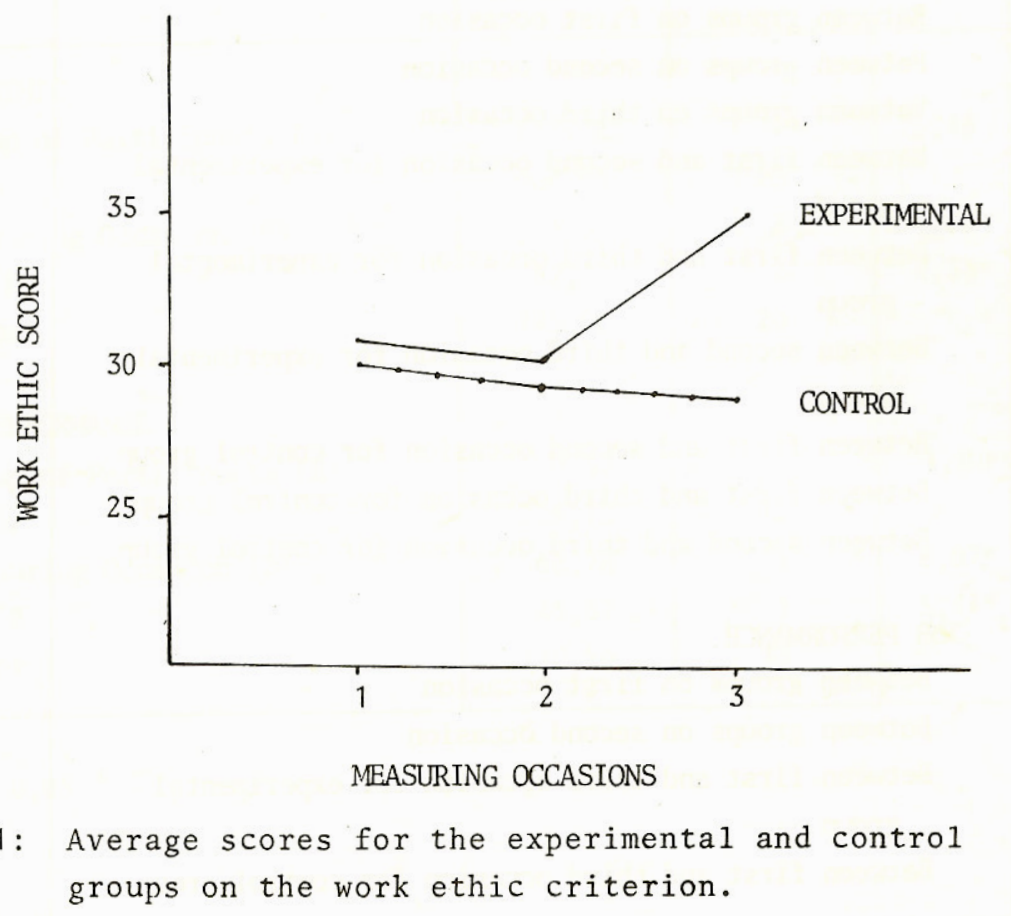

Table 2 indicates a significant interaction regarding job performance between the levels of treatment and the time of measurement. The results of the subsequent $t$ tests are shown in Table 3 as well. The only significant differences appear to be between the first and third job performance measurement of the experimental group. The results are graphically illustrated in Figure 2.

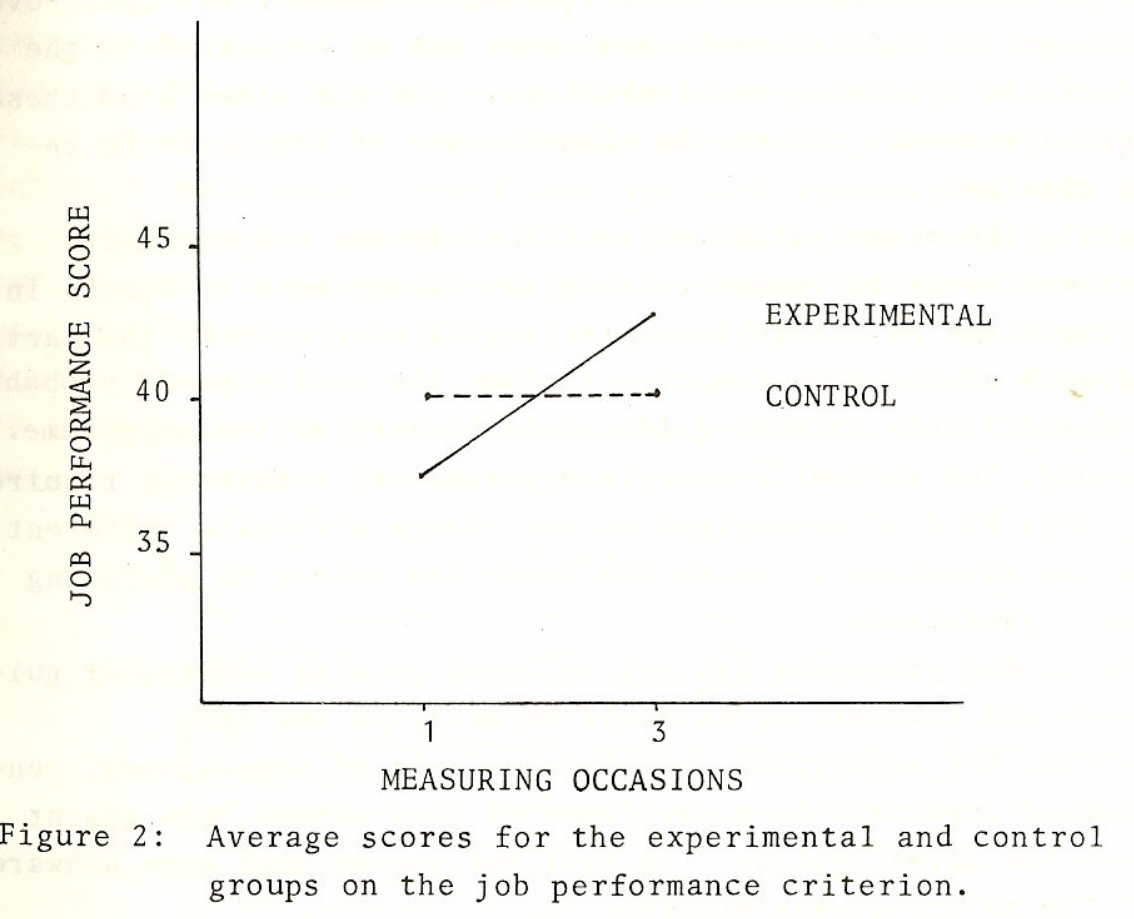


The evidence resulting from this study seems to indicate that the proposed programme has potential in the elimination of differences in work ethics. Specifically the programme has been shown to have a positive effect on the values which individuals attach to work in general. This change was also reflected in the job performance of the individuals. Although the programme was not designed directly to affect job satisfaction, work alienation, attitude towards supervisor and degree of westernisation and acceptance of authority, it was hoped that possible side effects in these areas would result from the programme. This expectation, however, was not realised. The failure to demonstrate spill-over effects on the indices mentioned above may be explained in the light of the following considerations. (On the other hand these may simultaneously add to the significance of the positive results obtained.)

- First, the organisation where the study was conducted at present seems to concentrate on the advancement of Blacks in occupations at a much lower level than were held by the participants in the study. So much so that the participants probably had difficulty in seeing the applicability of the programme.

- Second, the virtually sterile experimental conditions required by this kind of investigation may create a climate different to the situation in which the focus was solely on providing valid assistance.

- Third, the programme was not followed up with additional guidance and counselling as would normally be the case.

- Fourth, the supportive, reinforcing role of supervisors, considered important in a programme of this nature, was absent from the investigation. In fact the supervisors were unaware of the nature of the project.

\section{CONCLUSIONS}

Changes in the composition of a labour force, particularly at higher occupational levels involving different racial groups brings with it the responsibility to ensure that previous standards of overall performance are maintained, if not improved. By implication this requires not only the ability to delegate and to share, but also the ability to assume the challenges inherent in progress.

This study was performed on the premises that the adjustments associated with such change may be facilitated by reducing discrepancies related to the work qualities expected in 
a particular work role. On a theoretical level work values (ethics) surfaced as an important area capable of creating unwanted discrepancies. This study showed that the work values of Blacks may be changed to the extent that they reflect positively in their job performance as perceived by their supervisors. While the specific nature of challenges associated with the advancement of Blacks may vary from situation to situation, it seems feasible to include the question of work ethics in such analysis and if need be to provide for assistance on this level.

\section{ABSTRACT}

The increased merging of Blacks in the South African world of work has important implications for the industrial psychologist. Some of these are related to creating opportunities for advancement, labour and human relations, training and so on. In this study the question of work ethics was examined. It was found that work values which may be associated with work ethics, can be changed to the extent that it positively reflects in work performance.

\section{REFERENCES}

Aldag, J. \& Brief, P. Some correlates of work values. Journal of Applied Psychology, 1975, 60(6), 757-760.

Beatty, W. \& Schneier, C. Personnel Administration: An Experimental Skill Building Approach. Philippines: Addison-Wesley Publishing Company, Inc., 1977.

Biesheuvel, S. The measurement of African attitudes towards European ethical concepts, customs, laws and administration of justice. Journal of the National Institute for Personnel Research, 1955, 6, 5-17.

Blood, R. Work values and job satisfaction. Journal of Applied Psychology, 1969, 53(6), 456459.

Bouma, D. Beyond Lenski: A critical review of recent "Protestant Ethic" research. Society for the Scientific Study of Religion, 1973, 12, 141-155.

Green, W. (Ed.) Protestantism and Capitalism: The Weber Thesis and Its Critics. Boston: D.C. Heath and Company, 1959.

Kirk, E. Experimental Design: Procedures for the Behavioral Sciences. Belmont, California: Brooks/Cole Publishing Company, 1968.

Lenski, G. The Religious Factor: A Sociological Study of Religion's Impact on Politics, Economics, and Family Life. New York: Doubleday \& Company, Inc., 1961.

Mirels, L. \& Garrett, B. The Protestant ethic as a personality variable. Journal of Consulting and Clinical Psychology, 1971, 36(1), 40-44.

Robinson, P., Athanasiou, R. \& Head, B. Measures of Occupational Attitudes and Occupational Characteristics. Ann Arbor, Michigan: University of Michigan, Survey Research Center, 1969.

Weber, M. The Protestant Ethic and the Spirit of Capitalism. (Trans. by T. Parsons). New York: Scribner's, 1950.

Wollack, S., Goodale, J., Wijting, J. \& Smith, P. Development of the survey of work values. Journal of Applied Psychology, 1971, 55(4), 331-338. 